\title{
Crosstalk between food components and microRNAs: Role in metabolism, nutrition, health and diseases
}

\author{
Simardeep Kaur and Suresh Kumar* \\ Division of Biochemistry, ICAR-Indian Agricultural Research Institute, New Delhi, India
}

\begin{abstract}
Human health is significantly affected by dietary patten, nutritional habits, quality of food, and lifestyle. The diets enriched with bioactive food components like polyphenols, vitamins, minerals, polyunsaturated fatty acids, butyrate, and other dietary fibers are generally associated with a lesser incidence of chronic diseases such as cancer, cardiovascular disorders, and obesity. Apart from being antioxidants, some of these bioactive dietary components have the potential to regulate several cellular signaling pathways, modulate gene expression, affect transcription factors, and alter the microRNAs profile. MicroRNA (miRNA) is a non-coding-RNA that regulates the expression of its target gene(s) through its catalytic/regulatory functions. The miRNA is generally synthesized endogenously but it can also be obtained through dietary components that can change the expression of other genes. miRNA targets the specific mRNA, modulates expression of the gene(s) via binding to its complementary regions; thus, down-regulates the expression of the genes. Dietary food components impact cellular differentiation processes, proliferatory pathways, and pathophysiological conditions; thus, have the potential to affect the activity of genes associated with chronic diseases including cancer, cardiovascular diseases, and obesity by modulating the associated signaling pathways. This review discusses the role of dietary food components like polyphenols (quercetin, resveratrol, curcumin, $\alpha$-mangosteen, and epigallocatechin gallate), vitamins (A, D, and folic acid), Omega-3 polyunsaturated fatty acids, butyrate, and minerals (selenium, zinc) in modulating miRNA expression and their potential in causing chronic diseases.
\end{abstract}

\section{Introduction}

Understanding the response of the human body to dietary components and other environmental factors unravels the roles of the environment on gene expression, and presents the opportunities to modulate metabolism, health, and diseases based on nutrition. Foods are known to provide a conditioning environment to shape the activity of the genome and physiology of the body [1]. A better understanding of the influence of nutrients on gene expression might help to manage a healthy life. The role of the environment in modulating gene expression comes through epigenetic changes, and if epigenetics is contemplated as a harmonizing process, many of the phenotypic variations can be easily explained [2]. Epigenetic variations (total of all the changes in genetic material without altering the underlying nucleotide sequence) including modifications in chromatin architecture, histone protein, DNA methylation, and non-coding RNA biogenesis affect gene expression [3]. Non-coding RNAs play a very important role in epigenetic modifications and gene regulation. More importantly, some of the epigenetic changes may be inherited to the next generation that might result in phenotypic variations [4]. It is becoming apparent that changes in the epigenome of living organisms play a crucial role in tolerance to environmental stresses, nutrient availability, and evolution processes [5]. Research on nutriepigenomics justifies the direct association between dietary nutrients and epigenetic variations. Epigenetic changes are gaining exceptional importance because of the ability of bioactive food components to affect the epigenetic status of gene/genome [6]. Bioactive food components can alter the epigenetic pattern via their availability. Nutrients like folic acid, vitamin- $B_{12}$, methionine, and choline affect the epigenetic modifications through one-carbon metabolism [7]. Certain bioactive food components affect S-adenosylmethionine (AdoMet) or S-adenosylhomocysteine (AdoHcy) level in the tissue which alter methylation of DNA/histone proteins [8].
Decades ago, it was postulated that mRNA is a messenger and key player in the central dogma of molecular biology, as it connects a gene to a functional protein. However, subsequent studies led to the discovery of certain other unique RNAs that play a vital role in gene expression and regulation, but do not code for a protein; hence, termed non-coding RNAs (ncRNAs). One of the most common examples of ncRNAs is microRNAs (miRNAs). MicroRNAs are short (generally 22 nucleotides) in length, and the majority of them are involved in the down-regulation of gene expression at the post-transcriptional level $[9,10]$. In the majority of the cases, miRNA silences the gene expression via interacting with mRNA based on the complementarity between the bases of miRNA and mRNA, generally target at the 3' UTR region. This constitutes another way for gene regulation in living organisms including plants and mammals. Such a method of regulation of gene expression helps to fine-tune the expression of genes under varying environmental conditions. Within a decade, hundreds of miRNAs have been discovered in both plant and animal systems which possess highly conserved sequences and play important roles in the cell, tissue, and organ development, physiology as well as phenotype of the individual. Thus, miRNAs play important roles in regulating the expression of genes that in turn affect a variety of metabolic processes in an individual [11].

*Correspondence to: Suresh Kumar, USDA Norman E. Borlaug Fellow, IUSSTF Fellow, Principal Scientist, Division of Biochemistry, ICAR-Indian Agricultural Research Institute, New Delhi-110012, India. Tel: +91 11 25842038; Fax: +91 112584 6420; E-mail: sureshkumar3_in@yahoo.co.uk; sureshkumar@iari.res.in

Key words: dietary component, microRNA, nutrition, polyphenols, vitamin, fatty acid, mineral, cardiovascular disease, inflammation, cancer, obesity

Received: September 17, 2020; Accepted: October 26, 2020; Published: October 30 2020 
Studies on miRNA demonstrate the potential of bioactive dietary components like polyphenols, vitamin $\mathrm{A}$ and $\mathrm{D}$, folic acid, butyrate, polyunsaturated fatty acids (PUFA), and minerals in modulating the expression of miRNA, thus, regulating gene expression and the phenotype [12-16]. Some of the polyphenols such as quercetin, curcumin, resveratrol, and catechins regulate the expression of many miRNAs. Thus, such bioactive food components in our diet play an important role in miRNA expression and influence metabolism and physiology. However, the role of miRNA as a metabolic regulator is yet to be established, and it is still considered to be an emerging area of research/discussion. Comparative studies on examination of the effect of Western and Mediterranean diets on miRNAs expression indicate an association between the diets and diseases through modulation in miRNA expression (Figure 1). Recent studies indicate the modulation of miRNA expression in several diseases like cancer, cardiovascular issues, inflammation, and obesity [10,17-19]. Thus, miRNAs can serve as potential biomarkers as well as therapeutic strategies for diseases. The present review discusses the available information on the role of bioactive dietary components in regulating miRNA expression. Biogenesis of miRNAs and their role in cellular metabolism, followed by the crosstalk between miRNA and the dietary components (polyphenols, vitamins, minerals, and fatty acids). Finally, their role in the modulation of gene expression is discussed with the help of in vitro and in vivo research studies. The importance of miRNAs in diseases like cancer, inflammation, cardiovascular problems, and obesity is also discussed in the subsequent sections. We speculate that a better understanding and unraveling of the action of various dietary components on miRNA expression would help to prevent/treat various diseases.

\section{Origin, biogenesis, and role of miRNA in modulating gene expression}

Since the discovery in Caenorhabditis elegans, miRNA has been considered as a regulator of biological pathways occurring in diverse organisms [20]. Synthesis of miRNA starts in the nucleus, where RNA polymerase II transcribes it. The generated transcript is nearly 70 nucleotides long and known as pri-miRNA. The pri-miRNA takes a stem-loop or hairpin structure after folding, and it is transported out from the nucleus with the help of Exportin 5 in a Ran-GTP dependent manner to the cytoplasm. In the cytoplasm, Dicer RNase and TRBP (TAR-RNA binding proteins) cleave the pre-miRNA and form a doublestranded RNA. One of the strands of the double-stranded RNA serves as mature miRNA and recruited with argonaute (AGO) proteins to form an RNA-induced silencing complex (RISC). The complementary strand (passenger strand) is degraded. The miRNA binds to target mRNA at 3' UTR through imperfect complementarity which leads to translational repression and/or mRNA degradation (Figure 2) $[9,21,22]$.

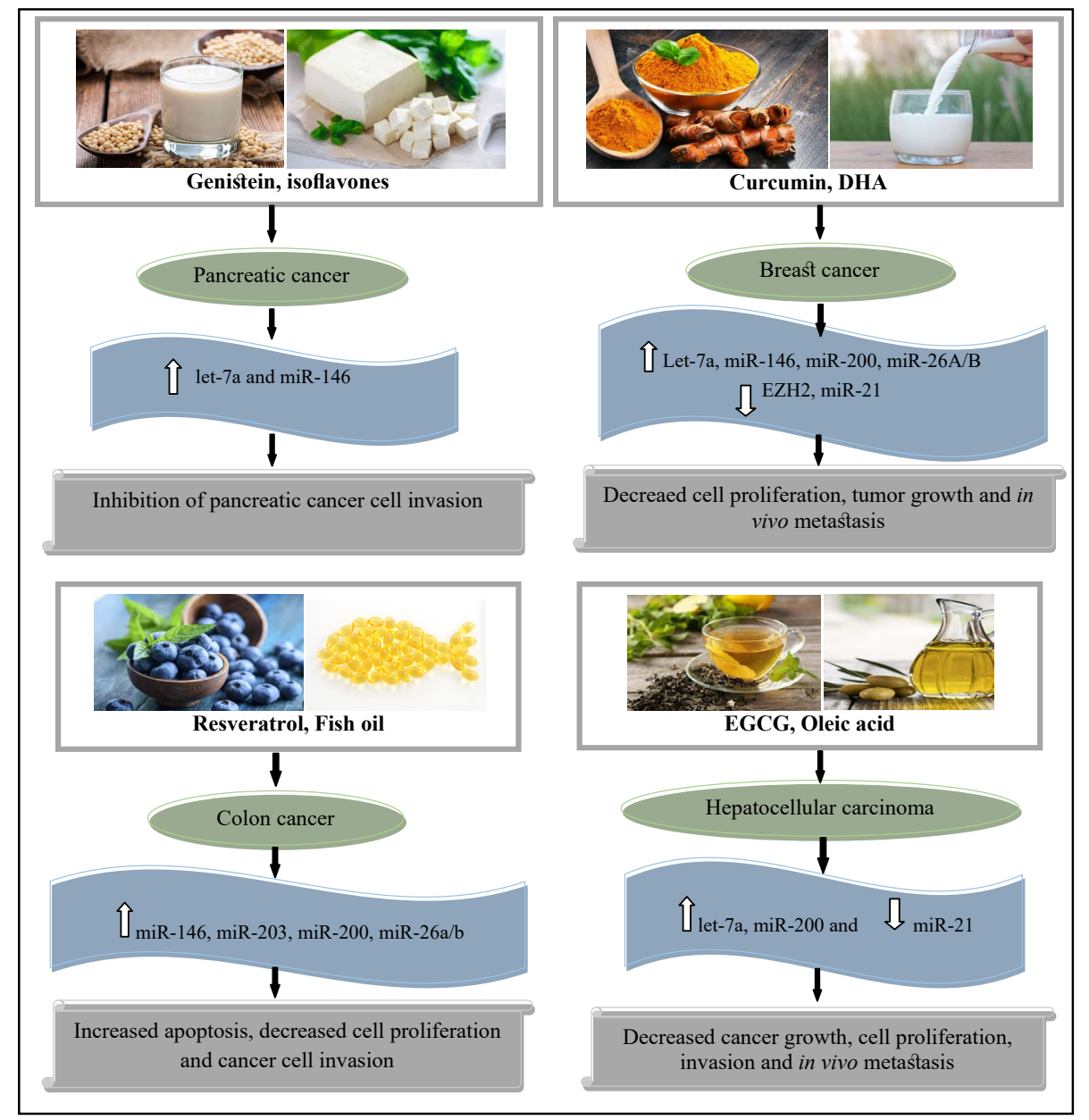

Figure 1. Role of the dietary components in modulating the miRNAs in cancer prevention (EGCG, Epigallocatechin gallate; DHA, Docosahexanoic acid). Upward arrows represent upregulation of miRNAs while downward arrow indicates down-regulation of miRNAs 


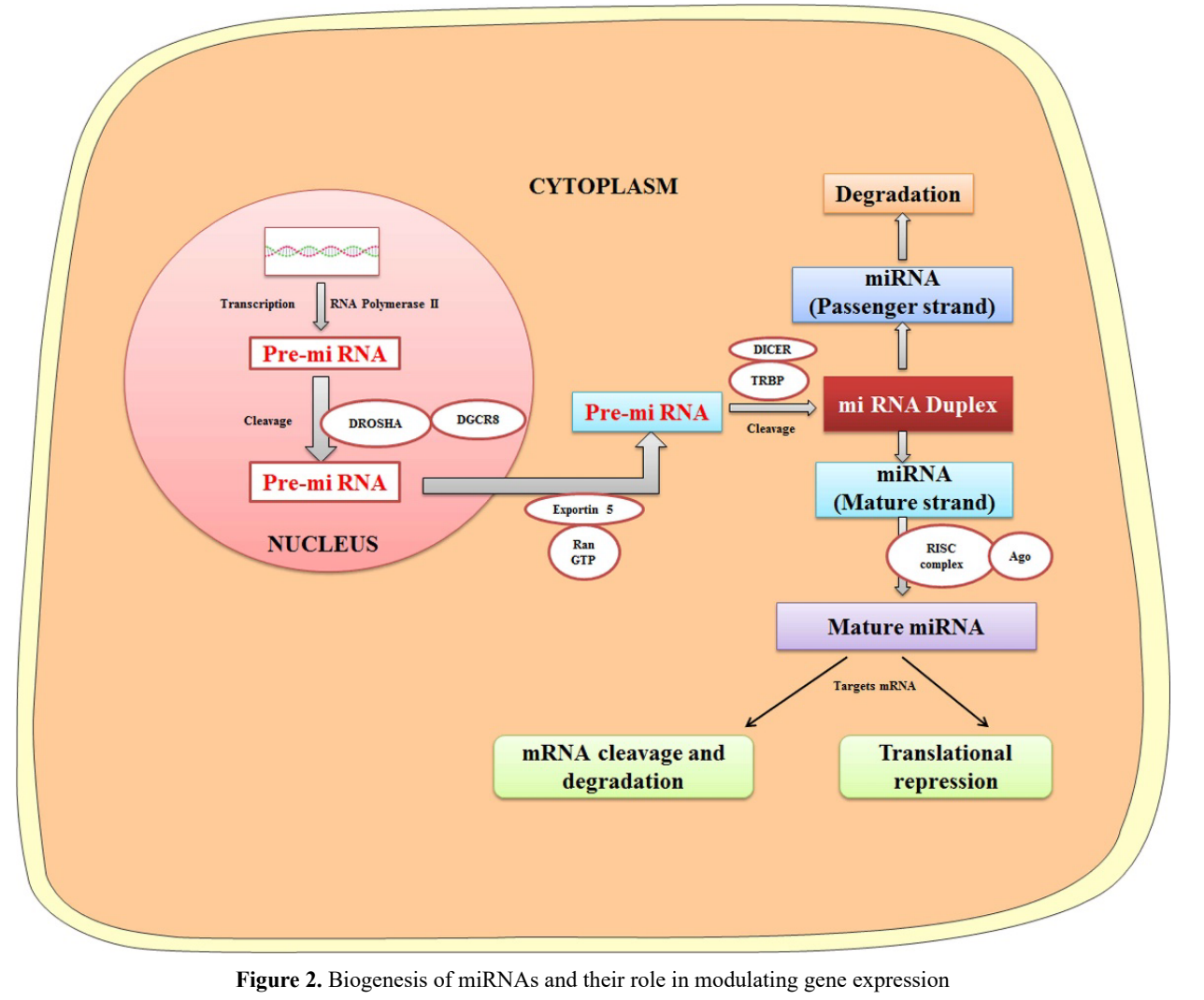

\section{Role of miRNA in cellular metabolism}

A tightly regulated metabolic network plays important role in metabolic homeostasis in higher organisms through sensing physiological and environmental stimuli [11]. Metabolic homeostasis is maintained by nutrition/energy intake and controlling the expression of genes to regulate metabolic activities. Certain exothermic and endothermic processes in the body are regulated to allow proper growth and development via the synthesis of different macromolecules like nucleic acids, lipids, proteins, and carbohydrates. Such regulation helps to prevent pathological conditions such as obesity, heart failure, type 2 diabetes, and cancer [10]. The ncRNAs like miRNA play a very important role in regulating the metabolic pathways which are required for energy homeostasis. Studies suggest a direct linkage between miRNAs and metabolic stimuli [23]. Expression profiling of miRNA has become an interesting way to investigate the response of the body to a high-fat diet. Expression profile of 641 circulating miRNAs in plasma of mice revealed elevated expression of certain miRNAs in response to the dietary fat intake, which suggests an effective role of miRNA in systemic lipid metabolism [24]. Another study suggests that miRNA plays important role in maintaining cholesterol levels as well as signaling processes. The regulatory group of miRNAs like miR-19b, miR-33, miR378 , and miR-10b play important role in the signaling process. Certain compounds like quercetin, allyl-isothiocyanate, apigenin, curcumin, and resveratrol were found to suppress the inflammatory response by targeting miR-155 [25].

One of the most important metabolic pathways, i.e. glucose metabolism, is influenced by miRNA regulation. miRNAs have been found to play a significant role in insulin secretion by targeting the production of proteins engaged in the insulin signaling pathway [26]. miR-375 is known to be the first miRNA implicated in insulin signaling.
Myotrophin and phosphoinositide-dependent kinase-1, responsible for the secretion of insulin, are targeted by miR-375 [27,28]. Homeostasis of glucose depends on the balance between glucagon and insulin secretions, which are secreted from different ( $\alpha$ and $\beta$ ) cells in the pancreas, and their expression is controlled through miR-375 activity. miR-103 and miR-107 are known to regulate the expression of a key insulin receptor caveolin 1 (CAV1). Other miRNAs, like let-7, also play a significant role in glucose metabolism in mice $[29,30]$. The number of miRNAs that regulate numerous components of insulin signaling and glucose metabolism is continuously expanding in different body tissues. miR-195 was reported to play a significant role in suppressing the expression of the insulin receptor, which results in impaired insulin signaling and synthesis of glycogen in cell culture [31]. Similarly, miR143, miR-378, and miR-802 have been reported to be involved in the regulation of glucose metabolism as well as insulin sensitivity [32,33].

\section{Effects of dietary components on modulation of miRNA}

The importance of dietary food components in nutrition and health [34], as well as their role in modulation of miRNAs, is becoming evident [35]. Various bioactive food components influence the biogenesis of miRNAs, it is quite factual to presume that some of the dietary components modulate susceptibility, growth, and progression of diseases. In this section, we discuss the impact of dietary polyphenols, vitamins, fatty acids, and minerals in crosstalk with miRNAs to play important role in metabolism, health, and chronic diseases (Figure 3).

\section{Quercetin}

Quercetin is a naturally occurring flavonoid present in many foods like onions, red wine, green tea, and apples. The protective effects of quercetin are generally pleiotropic and multi-faceted on human health 
even from the epigenetic point of view. When female mice were fed with the diets rich in quercetin in an experiment, it significantly increased the expression of miR-125b (known to be a negative regulator of the inflammation-related pathways) and miR-122 (involved in lipid homeostasis) ]36]. Studies on different cancer cells suggest enhanced expression of let-7c, let-7a, miR-142-3p, and miR-200b-3p in pancreatic ductal adenocarcinoma [37-39]. Expressions of miR-16, (potential down-regulator of Claudin-2), miR-145 (targeting/inhibiting the genes involved in apoptosis), and miR-217 (activates sensitivity to cisplatin and interferes with KRAS pathway) are altered by quercetin in lung adenocarcinoma, osteosarcoma, and ovarian cancer cells, respectively [40-42]. Quercetin was also reported to increase miR-146a expression in human breast cancer cells [43]. Thus, a lot of research requires to be carried out on evaluating the therapeutic application of polyphenols to modulate miRNAs against cancer.

\section{Catechin}

Catechins and their functional derivatives are believed to have healthpromoting effects by modulating miRNA biogenesis. Several isomers of polyphenol like catechin, gallocatechin, gallocatechin gallate (GCG), catechin gallate (CG), epicatechin gallate (ECG), epigallocatechin, and epigallocatechin gallate (EGCG) are found. However, EGCG is the most active and frequently present polyphenol found in green tea. Moreover, EGCG is the only polyphenol that is present in abundance in plasma in the free form [44]. Studies also suggested that EGCG is a potential repressor of biogenesis of five different miRNAs (miR-30b, miR453, miR-520-e, miR-629, and miR-608). These miRNAs contribute to various pathways like glycolysis, gluconeogenesis, metabolism of glutathione, oxidative phosphorylation, signaling of insulin, and pathways associated with inflammation [45]. EGCG was reported to regulate differential expression of 36 human miRNAs (19 up-regulation while 17 down-regulated) in human osteoarthritic cartilage-derived chondrocytes which are activated by IL-1 $\alpha$. EGCG was also reported to up-regulate miR-140-3p and miR221 biogenesis in melanoma and hepatoma cell lines, respectively; thus, suppress osteopontin in inducedliver fibrosis [46,47]. In humans, dermal papilla cells of scalp hair become highly sensitive in migraine with down-regulated expression of miR-590-5p, which could be restored through dietary supplementation of EGCG [48].

\section{Curcumin}

Curcumin is a polyphenol compound found in abundance in Curcuma longa L. (turmeric). It is an important dietary compound having anti-carcinogenic, anti-microbial, anti-oxidant, antiinflammatory, and chemo-preventive properties. Curcumin has been reported to enhance apoptotic signaling processes by activating the p53 gene and reducing TNF- $\alpha$ level; thus, it induces apoptosis and inhibits cell proliferation. The apoptotic effect of curcumin is mediated through modulation of miR-16, miR15a, and miR21 [49,50]. Study shows that when oesophageal cancerous cells are exposed to curcumin, they depict the enhanced expression of tumor suppressor let-7a, which in turn affects the caspase-3, Bcl-2, and Bax levels [51]. When pancreatic cells are exposed to curcumin, they show decreased expression of 18 different miRNAs and enhanced expression of 11 other miRNAs. The

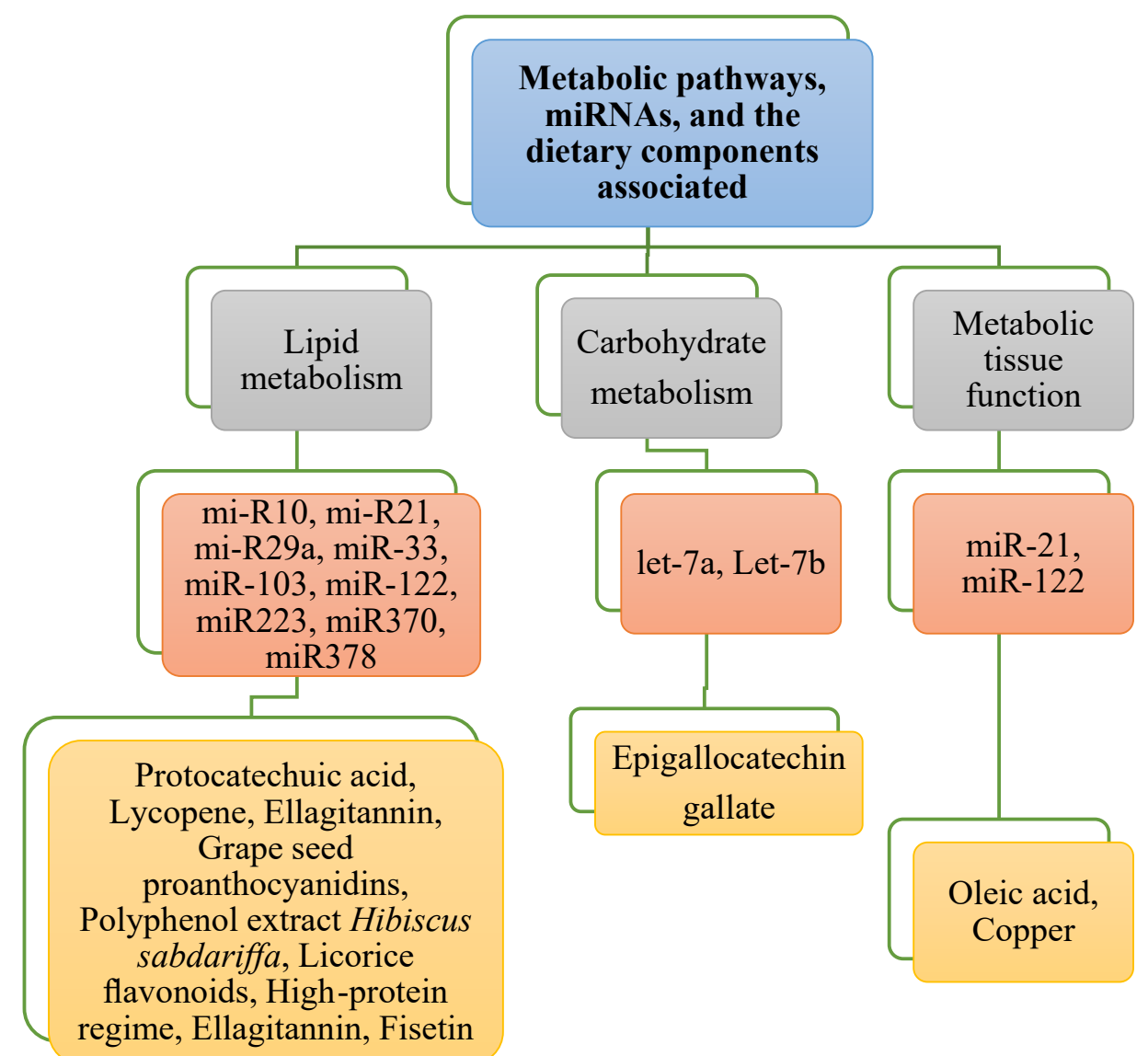

Figure 3. Modulation of various miRNAs in response to dietary nutritional inputs in metabolism 
increased expression of miR-22 resulted in the inhibition of estrogen receptor 1 and the SP1 transcription factor [52]. When lung cancer cells were treated with curcumin, an up-regulated expression of miRNAs was observed. miR-9, miR-205, miR-200a/b, miR-15a/16-1, and miR-203 also showed up-regulated expression in ovarian, prostate, hepatocellular, leukemia, and bladder cancer cells, respectively, when treated with curcumin. The breast cancer cells treated with curcumin showed up-regulated expression of miR-181b [53]. Modulation in miR-181b expression is linked with decreased expression of proinflammatory cytokines, CXCL-1, and CXCL-2, causing a suppressive effect on invasion and metastasis of the cells. Besides, curcumin also modulates the miRNAs involved in other processes associated with different chronic diseases. In a study on 3T3-L1 cells, miR-17-5p was found to up-regulate adipogenic differentiation. More importantly, treating the cells with curcumin caused the down-regulated expression of miR-17-5p, and increased stimulus of the target in the cell line [54]. Recently, thyroid cancer cells treated with curcumin, showed up-regulated expression of miR-21 and miR-200c, while let-7c, miR26a, miR-215, miR-192-5p, and miR-125b were reported to be downregulated [55].

\section{Resveratrol}

Resveratrol is found abundantly in wine, berries, and grape skins. It is known to promote health benefits by its antiviral, chemo-preventive, anti-oxidant, and anti-inflammatory properties [56]. A study on SW480 human colon cancer cells led to the finding that the expression of a set of 46 different miRNAs was modulated by resveratrol [57]. At the cellular level, resveratrol prevents cancerous cell growth by up-regulating miR34a expression, which down-regulates E2F3 and its downstream target Sirt1 [58]. Numerous reports have confirmed the role of resveratrolmediated alteration in miRNAs expression in the prevention of various chronic diseases like cancer. Resveratrol significantly decreases the level of miR-17, miR-21, miR-25, miR-92a-2, miR-103-1, and miR-103-2 in studies on human colon cancer [59]. In melanoma and prostate cancer, resveratrol was reported to decrease the level of miR-221 [60,61], whereas, in lung tumors, resveratrol up-regulated miR-200c [62]. It was also found to suppress miR-542-3p and activate miR-122-5p in estrogen-responsive cells [63]. Resveratrol acts through miRNAs not only in diseased cells like cancer but also in white adipose cell lines.

\section{Mangostin}

A polyphenolic xanthone-derived bioactive compound known as a-Mangostin is found in the pericarp of Garcinia mangostana. Studies suggest that xanthones play important roles as anti-oxidative, antiproliferatory, anti-inflammatory agents, and also work against cancer because of being potent chemopreventive agents $[64,65]$. However, a significant cytotoxic effect of $\alpha$-mangostin on DLD-1 cells, due to its association with the up-regulation of miR-143 which negatively affects Erk5 translation, was reported [66]. Another study suggests that expression of miR-133B significantly decreased in DLD-1 cells when exposed to a-mangostin, hence its target gene (death receptor5, DR5), showed up-regulated expression [67].

\section{Prospects of vitamin supplementation on altered expression of miRNA}

A growing number of studies depict that vitamins are involved in the prevention of several diseases. Retinoic acid (bioactive form of vitamin A) plays a vital role in immunological processes, cellular differentiation, and vision. Vitamins also act as tumor suppressors in breast, bladder, prostate, lung, and liver cancers $[15,68]$. A study on embryonic stem cells of a mouse treated with retinoic acid showed significant up- and down-regulation of 31 and 175 different mi-RNAs, respectively. Among the down-regulated miRNAs, miR-220b and miR200c could remarkably elevate the expression of certain pluripotent genes like Oct4 and Nanog associated with the developmental process [69]. When leukemia cells were treated with retinoic acid, it resulted in a marked increase in the expression of miR-342, miR-223, miR-107, let-7d, let-7c, let-7a-3, miR-16-1, miR-15b, and miR-15a. On the other hand, decreased expression of miR-181b, miR-193, miR-93, miR-25, and miR-17 was also reported [70,71]. When breast cancer cell, MCF-7, was treated with retinoic acid, it inhibited its cellular proliferation by altering miR-21 expression [72].

Studies also suggest that the active form of vitamin D, di-hydroxy vitamin $\mathrm{D}$, has the potential to regulate miRNAs expression. The dihydroxy vitamin D binds to its receptors (vitamin D receptors, VDRs) which facilitate the maturation of several miRNAs by modulating the genes involved in their biogenesis, stability, and developmental processes $[16,73]$. In association with its metabolites, vitamin D can exert chemoprotective effects by altering the expression of various miRNAs $[74,75]$. When human myeloid leukemia cells were treated with vitamin D3, it was observed that expression of miR-181-b and miR-181a was decreased. Vitamin D also possesses the ability to up-regulate the expression of miR-32, which suppresses apoptosis induced by factors like Bim [76]. Vitamin D also decreases inflammation by targeting miR-155 which is negatively correlated with VDRs [77]. Calcitriol and paricalcitol (activators of VDRs) were reported to have the potential to inhibit the expression of miR-29b and miR-30c in nephrectomized rats. These miRNAs are responsible for the termination of cardiac fibrosis by targeting COL1A1, CTGF, and MMP-2 expression [78].

Folic acid, present in ample amount in fruits, vegetables, and various grains, plays important role in the synthesis and repair of DNA, as well as in the DNA methylation process. A study on rats suggests that when male fisher rats were fed with a diet deficient in folic acid, hepatocellular carcinoma was developed after 54 weeks even in the absence of any kind of carcinogen [12]. Development of the cancer was linked with the up-regulation of miRNAs like let-7a, miR-21, miR- 23, miR-130, miR-190, and miR-17-92. Besides, down-regulation of miR122 was reported behind the tumor development in the liver compared to that in the counterpart fed with a sufficient amount of folate in their diet. More importantly, after 36 weeks of folate supplementation, the level of miR-122 was replenished/up-regulated, and liver tumorigenesis was suppressed. Thus, the studies suggest that folic acid can be used for therapeutic chemo-preventive interventions [79].

\section{Fatty acids and miRNA biogenesis}

Polyunsaturated fatty acids like Omega-3 PUFAs are found in fish oil, seed oil, soybean, and walnut. Clinical studies show that they play protective roles against cancers like colorectal cancer. Higher intake of diets rich in these fatty acids has the potential to inhibit the growth of colon cancer [80,81], breast cancer [13], and glioblastoma [81] by altering various signaling pathways and expression of genes. Growing evidence suggests that a diet enriched with omega- 3 fatty acid is associated with alteration of let-7 miRNAs that play important role in the regulation of proteins like caspase, Bcl-2, and MAPK [82]. The chemo-preventive nature of omega-3 fatty acid from fish oil might be due to its role in alterations of miRNAs present in the intestine. To understand the effect of omega-3 fatty acid on the altered profile of miRNAs in the colon of rat administered with a carcinogen azoxymethane, Davidson et al. [83] fed the rats with diets enriched in omega- 3 fatty acid. They observed 
the least alteration in the profile of let-7d, miR-15b, miR-107, miR191, miR-324-5p. Crim et al. [84] reported that the chemo-preventive effect of omega- 3 fatty acid is far more pronounced when pectin (more fermentable fiber) is added to the diet instead of cellulose (poorly fermentable fiber). They concluded that a diet rich in fish oil and pectin increases the expression of miR-19b, miR-26b, and miR-203 by downregulating the receptors such as IGF1, IGF2, and the transcription factor 4 [85]. Thus, the diet consisting of polyunsaturated fatty acid plays a key role in the prevention of cancers. Vinciguerra et al. [86] reported that certain unsaturated fatty acids decrease PTEN expression in liver cells and exposure to oleic acid results in the increased expression of miR-21. Furthermore, DHA causes down-regulation of miR-21 which is related to enhanced PTEN protein levels and lowest expression of CSF-1. Thus, the anti-oncogenic and chemoprotective functions of polyunsaturated fatty acids are mediated through modulation in miRNA biogenesis.

The fermentation of dietary fibers in the intestine produces shortchain fatty acid butyrate, which is chemoprotective [87]. Butyrate has the potential to inhibit cellular proliferation and to activate programmed cell death of colon cancer cells through miR-106b $[88,89]$. Expression of miR-106b-25, miR-18b, miR-106a, and miR-17-92 was reported to be significantly up-regulated in HCT 116 colon cancer cells when they were exposed to butyrate [90]. Thus, the antiproliferative and proapoptotic activities of butyrate are associated with alteration in the miRNAs profile.

\section{Influence of dietary minerals on miRNA expression}

Some of the minerals have the potential to affect miRNA biogenesis and thus are associated with several chronic diseases like cancer, cardiovascular diseases (CVDs), and diabetes [91,92]. Selenium is one such mineral, responsible for a wide range of functions and essential for proper physiological processes in humans [93]. A study conducted by Xing et al. [94] reported that Selenium deficiency is responsible for the down-regulated expression of 12 different miRNAs in the Caco-2 intestinal cell line. miR-185, miR-429, miR-203, and miR-625 were the most commonly affected miRNAs. The miR-374, miR-16, miR-199a5p, miR-195, and miR-30e, responsible for signal transduction, cellular differentiation, and responders of stress, were observed to be 5 -fold up-regulated under selenium-deficiency in rats compared to that in the control group (supplemented with selenium). Besides, 3 different miRNAs (miR-3571, miR-675, and miR-450a) were detected to be down-regulated [94].

Apart from selenium, zinc is also considered to be the elements required for the appropriate expression profile of miRNAs. It is required for the structural stability of numerous proteins since it acts as a cofactor for nearly 350 different enzymes [95]. In vivo study on rats showed that zinc-deficient caused up-regulated expression of inflammation-related genes and altered miRNAs profile in skin, pancreas, liver, and lung. The expression of two miRNAs (miR-21 and miR-31) associated with inflammation was dysregulated under zinc-deficiency compared to that in the zinc supplemented group [14]. During zinc deficiency in human miR-204 and miR-296-5p were reported to be down-regulated, and the effects were reversed after zinc supplementation. These miRNAs have been reported to suppress the expression of numerous oncogenes [96].

\section{Role of miRNAs in the occurrence of diseases}

The potential of dietary components in the modulation of miRNAs associate them with pathogenic conditions. Many of the miRNAs act as potential tumor suppressors $[97,98]$. The role of the miRNAs in regulating a broad range of cellular, molecular, and physiological processes in the cell that control growth, apoptosis, invasion, angiogenesis, and metastasis have been well-described earlier $[99,100]$. Evidence indicates that up- or down-regulation of these miRNAs is associated directly/indirectly with tumorigenesis and the development of different types of cancers. Thus, the miRNAs might be considered in finding out therapeutic interventions against severe chronic diseases like cancer [100-102].

\section{Role of miRNAs in cancer}

A large number of studies have evaluated the impact of bioactive dietary components on the regulation of miRNAs expression in different types of cancer cell lines. Some of the studies reported the importance of dietary patterns and calorie restrictions on the modulation of miRNAs expression and function [103]. Continuous intake of the Western diet, which targets the EGFR signals, and inhibit miR-143 and miR-145, leads to the increased incidence of colonic tumorigenesis and marked elevation of miRNA targets like K-Ras and MYC [103]. The role of dietary folic acid in the expression of miRNA in different model systems, its correlation with the occurrence of cancer, and prevention has also been studied [104]. More importantly, the addition of folic acid to reverse folate-deficiency reverses the altered profiles of miRNAs. This proves the important role of folic acid in the modulation of miRNAs and signifies that folate can be used as a potential nutrient in cancer prevention.

Gaedicke et al. [105] observed the importance of vitamin E in the regulation of miRNAs expression. The dietary deficiency of vitamin $\mathrm{E}$ for 6 months resulted in reduced expression of miR-122A and miR$125 \mathrm{~b}$ in the hepatic cells in rats. The study suggests that supplementing diets with the right amounts of vitamin E may have cancer-preventive property by modulating the miRNA expression [105]. miR-21 dysregulation has been linked with the induction and progression of different cancers, and it is modulated by curcumin [106]. Curcumin down-regulates miR-2 expression and exerts its chemo-preventive effects in different kinds of cancers. Reports indicate that miR-21 is one of the key players in cancer-linked pathways including cellproliferation, metastasis, drug resistance, and apoptosis [107-109]. Therefore, understanding the mechanisms involved in the modulation of miRNAs in response to dietary components might provide new insights in designing newer therapeutic interventions to fight against cancers (Figure 3).

\section{Role of miRNA in cardiovascular diseases}

Many research trials demonstrate that during CVDs several miRNAs are differentially expressed. The alteration in miRNA expression was reported in blood plasma and cardiac tissues. Research suggests that two miRNAs are involved in various CVDs [110-113]. In cardiac hypertrophy, miR-1 and miR-133 were observed to be downregulated which leads to cardiac injury [114]. miR-1 is responsible for the growth of cardiac myocytes, and regulate hypertrophy by inhibiting the signaling process [115].

Various other miRNAs that are associated with cardiac hypertrophy are included in Figure 4. miR-1 and miR-133 are associated with the pathology of cardiac arrhythmia where these miRNAs are up-regulated. The mouse suffering from cardiac fibrosis showed a marked increase in the expression of miR-21, and down-regulation of miR-21 could reverse cardiac fibrosis and improved the functioning of the heart to normal [116]. The patients suffering from coronary heart diseases showed a marked elevation in 3 different miRNAs (miR-1, miR-21, and miR- 
208). On the other hand, down-regulation of 6 different miRNAs (miR133, miR-126, miR-17, miR-155, and miR-195) was also reported in the patients (Figure 4).

\section{Role of miRNAs in obesity}

Studies suggest that epigenetic mechanisms play important role in obesity-related problems, and miRNA can be an important player as it can affect metabolic reprogramming [117]. The miRNAs that cause dysregulation of metabolic tissues in individuals with obesity play important role in the process of fat metabolism, secretion of insulin, differentiation, and synthesis of adipocytes, etc. $[118,119]$. Diets containing fruits and vegetables decrease the risk of obesity as they contain bioactive components that affect epigenetic mechanisms like DNA methylation, histone modifications, and siRNA/miRNA biogenesis. Obesity is a condition associated with chronic inflammatory processes that contribute to the pathogenesis of several other diseases [120]. A study indicates that miR-206, miR31-5p, and miR-2355-5p are differentially regulated in obese children compared to that in children with normal weight [121]. Besides, miRNAs are also involved in weightloss. Ortega et al. [122] reported post-surgery weight-loss due to the down-regulated expression of miR140-5p, miR-122, and miR193a-5p. Furthermore, miRNA-223 and miRNA-143 are responsible for changes in cellular metabolism during obesity in human beings [123]. Milagro et al. [124] reported that the level of miRNAs (e.g. miR-935 and miR-
$376 \mathrm{~b}$ ) in the blood is altered during diet-induced weight loss. Figure 5 summarizes the miRNAs involved in obesity and the targeted pathways.

\section{Conclusions}

Even though the current understanding of miRNAs biogenesis and their potential role in the regulation of gene expression, as affected by dietary food components, is advancing day-by-day, the mystery of the mechanism of action of miRNA continue to emerge. The presence of the bioactive food components in the diet is one of the major factors that affect the pathogenesis of diseases like cancer, CVDs, and obesity. Thus, diet plays a key role in regulating gene expression via alterations in miRNAs biogenesis. Prevention and cure of various chronic diseases via miRNA modulations through dietary food components is an emerging/interesting area of science. Studies suggest that specific bioactive food components like vitamins, polyphenols, minerals, and PUFAs have preventive effects on diseases like cancer and CVDs (Figure 6). However, the exact mechanism of action is still not fully understood.

The global population is increasing rapidly, and it is expected to cross 9 billion by the year 2050. Moreover, the changing dietary habits might result in an increasing demand for fresh foods to feed the burgeoning population with healthy diets [125]. Providing healthy foods for the ever-growing global population is not the only challenge, but producing them in a safe and sustainable manner is another

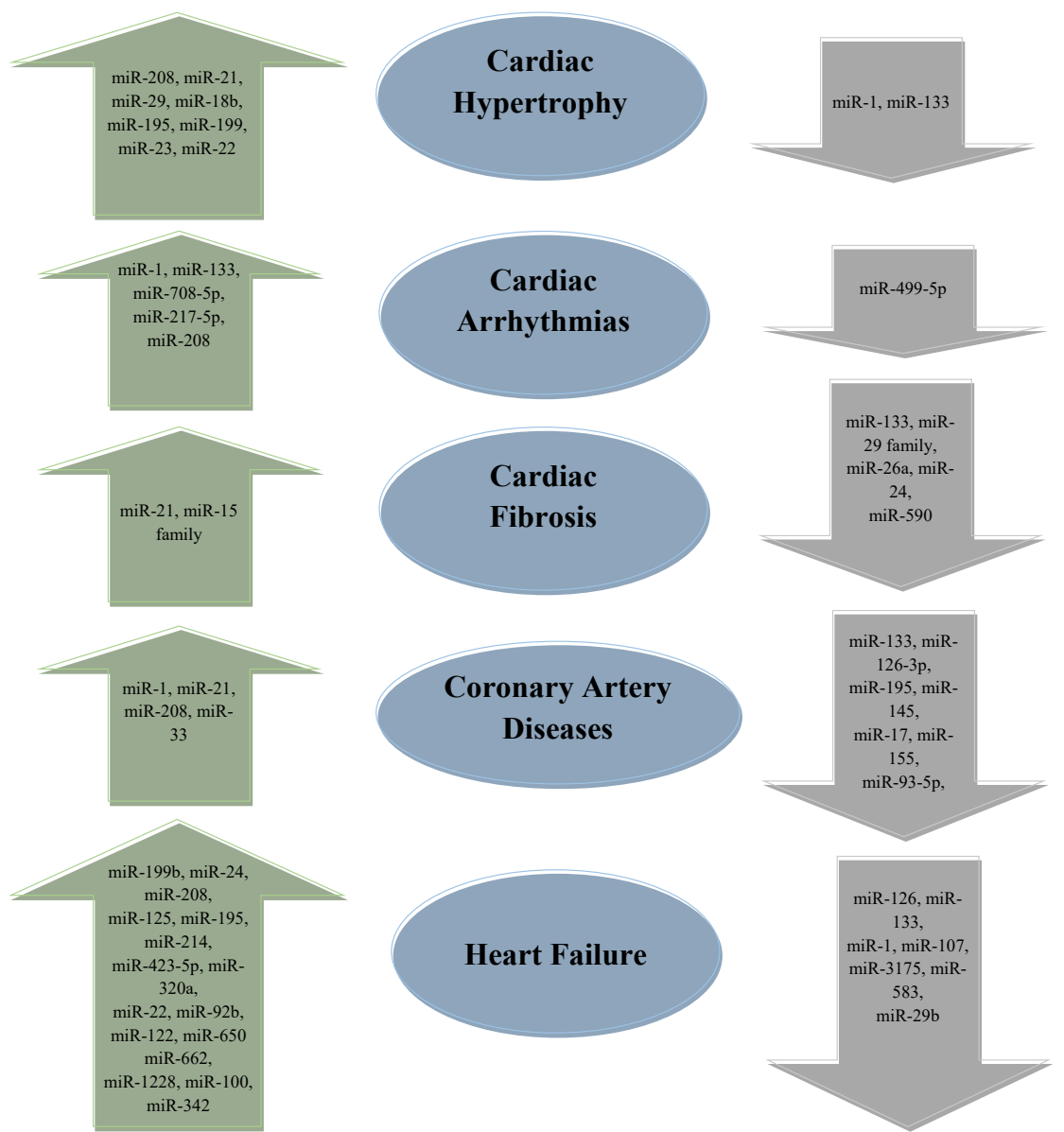

Figure 4. Dysregulation of miRNAs during different cardiovascular diseases (CVDs). miRNAs listed inside the arrow shows changes in expression during CVDs. Upward arrow indicates up-regulation of miRNAs, while downward arrow indicates down-regulation of mi-RNAs 


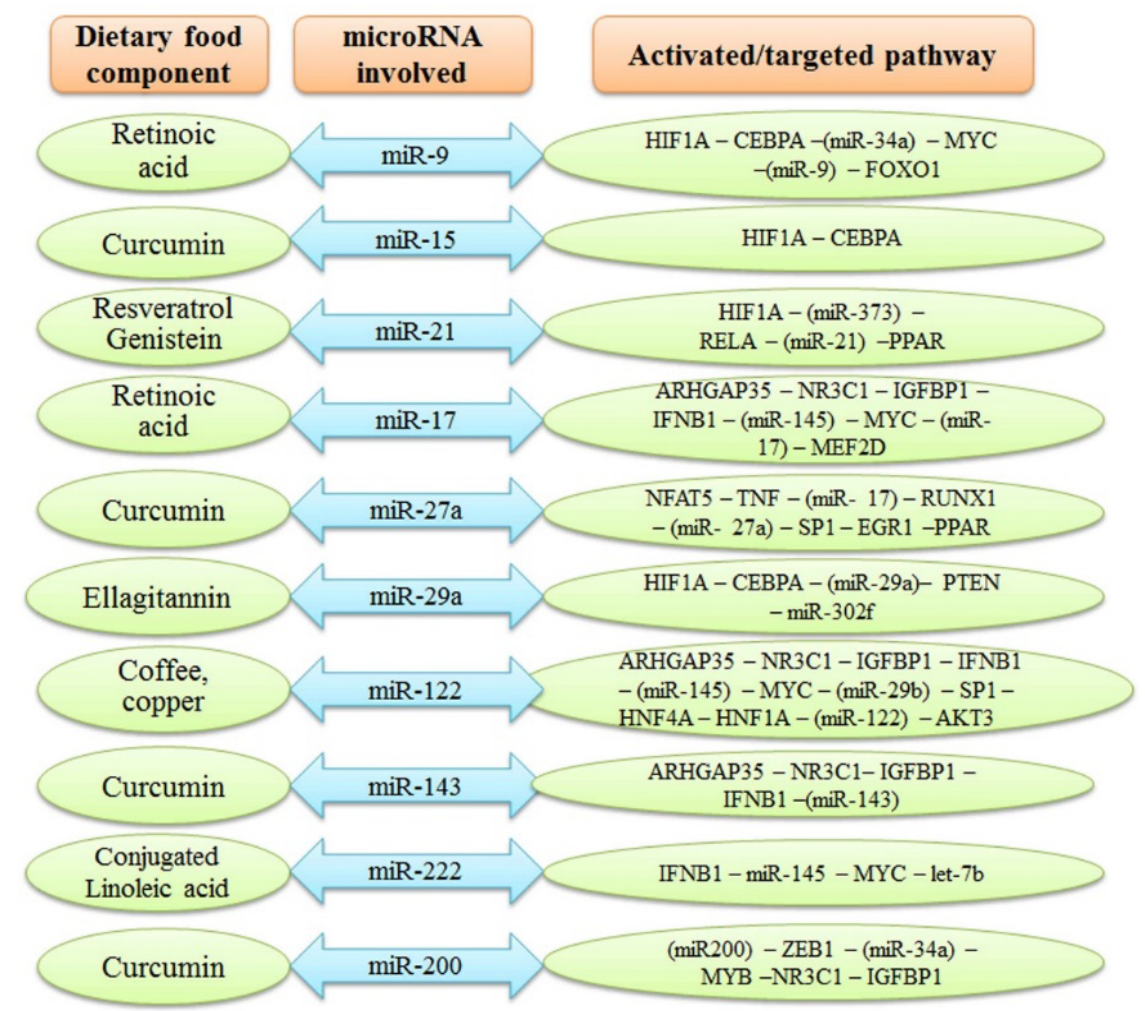

Figure 5. Role of the dietary bioactive food component in modulation of various miRNAs during obesity and their targeted pathways. (AKT3, AKT serine/threonine kinase 3; ARHGAP35, Rho GTPase activating protein 35; CEBPA, CCAAT/enhancer-binding protein Alpha; EGR1, early growth response protein 1; FOXO1, Forkhead box protein O1; HIF1A, hipoxia-inducible factor 1; HNF4A, hepatocyte nuclear factor 4-alpha; IFNB1, interferon beta 1; IGFBP1, insulin-like growth factor-binding protein-1; MEF2D, myocyte enhancer factor 2D; MYC, nuclear phosphoprotein in cell cycle; NFAT5, nuclear factor of activated T-cells 5; NR3C1, nuclear receptor subfamily 3 group C member 1; PPAR, peroxisome proliferator activated receptor gamma; PTEN, phosphatase and tensin homolog; RELA, proto-oncogene, NF-Kb subunit; RUNX1, runt related transcription facotr 1; TNF, tumor necrosis factor; ZEB1, zinc finger E-box binding homeobox 1)

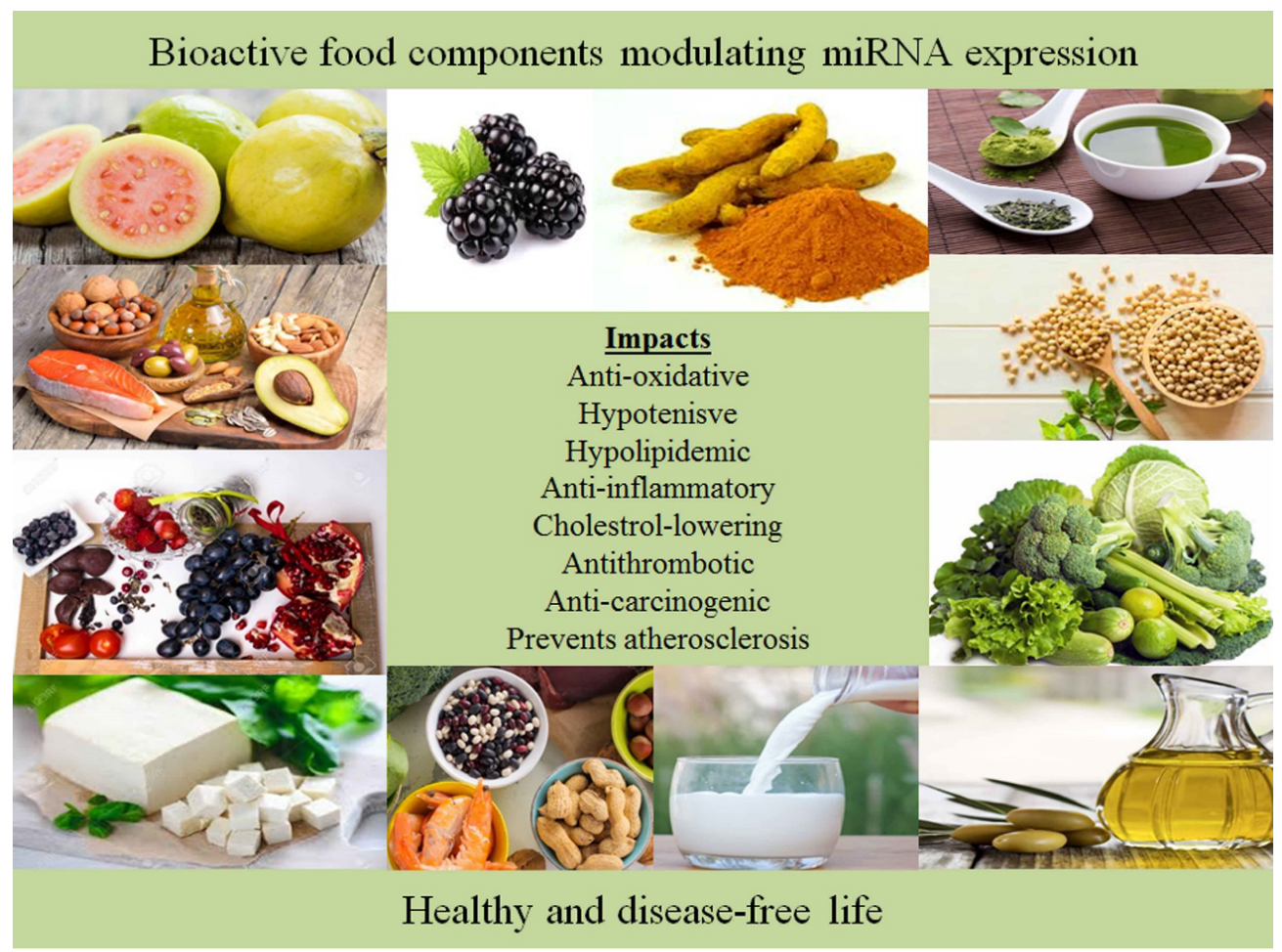

Figure 6. Dietary components that regulate miRNA expression and exert beneficial effects on human health 
important challenge. The on-going pest management strategies rely heavily on chemical pesticides, which not only cause adverse effects on the beneficial organisms but also affects human health as the pesticide remains in thus produced foods as residues [126]. Therefore, the need of the day is to use safe and sustainable pest management strategies like biopesticides to produce healthy foods and keep the environment safe [127]. miRNAs not only play important role in pathogenesis in animals, but they have equally important roles to play in causing diseases in plants [128]. Nevertheless, advances in emerging technologies like epigenomics and genome editing might help to produce healthy foods as well as modulating miRNA biogenesis or its target gene(s) $[129,130]$. However, it would be equally important to take care of the biosafety issues of laboratory research [131], as well as those of the genetically modified organisms [132] to protect the environment.

The views expressed here are those of the authors only, and these may not necessarily be the views of the institution/organization the authors are associated with.

\section{References}

1. Kaur S, Kumar S (2020) Nutriepigenomics: need of the day to integrate genetics, epigenetics and environment towards nutritious food for healthy life. Food Sci Nutri Tech 5: 000239 .

2. Kumar S, Chinnusamy V, Mohapatra T (2018) Epigenetics of modified DNA bases: 5-methylcytosine and beyond. Front Genet 9: 1-14.

3. Kumar S (2018) Epigenomics of plant responses to environmental stress. Epigenomes 2: 6 .

4. Kumar S (2018) Environmental stress, food safety, and global health: biochemical, genetic and epigenetic perspectives. Med Safety Global Health 7: e145.

5. Kumar S (2019) Epigenetics and epigenomics for crop improvement: current opinion. Adv Biotechnol Microbiol 14: 1-6.

6. Choi SW, Friso S (2010) Epigenetics: a new bridge between nutrition and health. Adv Nutri 1: 8-16.

7. Serefidou M, Venkatasubramani AV, Imhof A (2019) The impact of one carbon metabolism on histone methylation. Front Genet 10: 764.

8. Jin SG, Kadam S, Pfeifer GP (2010) Examination of the specificity of DNA methylation profiling techniques towards 5-methylcytosine and 5-hydroxymethylcytosine. Nucleic Acids Res 38: e125.

9. Krol J, Loedige I, Filipowicz W (2010) The widespread regulation of microRNA biogenesis, function and decay. Nat Rev Genet 11: 597-610.

10. Ross SA, Davis CD (2014) The emerging role of microRNAs and nutrition in modulating health and disease. Annu Rev Nutr 34: 305-336.

11. Hartig SM, Hamilton MP, Bader DA, McGuire SE (2015) The miRNA interactome in metabolic homeostasis. Trends Endocrinol Metab 26: 733-45.

12. Kutay H, Bai S, Datta J, Motiwala T, Pogribny I, et al. (2006) Downregulation of miR122 in the rodent and human hepatocellular carcinomas. J Cell Biochem 99: 671-678.

13. Dimri M, Bommi PV, Sahasrabuddhe AA, Khandekar JD, Dimri GP (2010) Dietary omega-3 polyunsaturated fatty acids suppress expression of EZH2 in breast cancer cells. Carcinogenesis 31: 489-495.

14. Alder H, Taccioli C, Chen H, Jiang Y, Smalley KJ, et al. (2012) Dysregulation of miR31 and miR-21 induced by zinc deficiency promotes esophageal cancer. Carcinogenesis 33: $1736-1744$.

15. Van Harten Gerritsen AS, Balvers MGJ, Witkamp RF, Kampman E, van Duijnhoven FJB (2015) Vitamin D, inflammation, and colorectal cancer progression: a review of mechanistic studies and future directions for epidemiological studies. Cancer Epidemiol Biomark Prev 24: 1820-1828.

16. Zeljic K, Supi G, Magic Z (2017) New insights into vitamin D anticancer properties: Focus on miRNA modulation. Mol Genet Genomics: 1-14.

17. Shah MS, Davidson LA and Chapkin (2012) Mechanistic insights into the role of microRNAs in cancer: influence of nutrient crosstalk. Front Genet 3: 1-14.

18. Quintanilha BJ, Reis BA, Silva Duarte GB, Cozzolino SMF, Rogero MM (2017) Nutrimiromics: role of microRNAs and nutrition in modulating inflammation and chronic diseases. Nutrients 9: 1-24.
19. Rajoka MSR, Jin M, Haobin Z1 Li Q, Shao D, Huang Q, et al. (2018) Impact of dietary compounds on cancer-related gut microbiota and microRNA. Appl Microbiol Biotechnol.

20. Beermann J, Piccoli M-T, Viereck J, Thum T (2016) Non-coding RNAs in development and disease: background, mechanisms, and therapeutic approaches. Physiol Rev 96: 1297-325.

21. Bohnsack MT, Czaplinski K, Gorlich D (2004) Exportin 5 is a RanGTP-dependent dsRNA-binding protein that mediates nuclear export of pre-miRNAs. RNA 10: 185191.

22. Vasudevan S, Tong Y, Steitz JA (2007) Switching from repression to activation: MicroRNAs can up-regulate translation. Science 318: 1931-1934.

23. Dumortier O, Hinault C, Van Obberghen E (2013) MicroRNAs and metabolism crosstalk in energy homeostasis. Cell Metab 18: 312-324.

24. Mantilla Escalante DC, López de Las Hazas MC, Gil Zamorano J, Del Pozo Acebo L, Crespo MC, et al. (2019) Postprandial circulating miRNAs in response to a dietary fat challenge. Nutrients 11: 1326

25. Shao D, Lian Z, Di Y, Zhang L, RajokaMSR, et al. (2018) Dietary compounds have potential in controlling atherosclerosis by modulating macrophage cholesterol metabolism and inflammation via miRNA. NPJ Sci. Food 2: 13.

26. Aghaei M, Khodadadian A, Elham K-N, Nazari M, Babakhanzadeh E (2020) Major miRNA involved in insulin secretion and production in beta-cells. Int J Gen Med 13: 89-97.

27. Esteller M (2011) Non-coding RNAs in human disease. Nat Rev Genet 12: 861-74.

28. Kim M, Zhang X (2019) The profiling and role of miRNAs in diabetes mellitus. $J$ Diabetes Clin Res 1: 5-23.

29. Frost RJA, Olson EN (2011) Control of glucose homeostasis and insulin sensitivity by the Let-7 family of microRNAs. PNAS 108: 21075-21080.

30. Zhu H, Shyh Chang N, Segre AV, Shinoda G, Shah SP, et al. (2011) The Lin28/let-7 axis regulates glucose metabolism. Cell 147: 81-94.

31. Yang WM, Jeong HJ, Park SY, Lee W (2014) Saturated fatty acid-induced miR-195 impairs insulin signaling and glycogen metabolism in HepG2 cells. FEBS Lett 588: 3939-46.

32. Vienberg S, Geiger J, Madsen S, Dalgaard LT (2017) MicroRNAs in metabolism. Acto Physiol 219: 346-361.

33. Zhang X, Schulze PC (2016) MicroRNAs in heart failure: non-coding regulators of metabolic function. Biochim Biophys Acta 1862: 2276-87.

34. Kumar S, Krishnan V (2017) Phytochemistry and functional food: the needs of healthy life. J Phytochem Biochem 1: 103.

35. Cui J, Zhou B, Ross S, Zempleni I (2017) Nutrition, microRNAs, and human health Adv Nutr 8: 105-12.

36. Boesch-Saadatmandi C, Loboda A, Wagner AE, Stachurska A, Jozkowicz A, et al (2011) Effect of quercetin and its metabolites isorhamnetin and quercetin-3-glucuronide on inflammatory gene expression: Role of mir-155. J Nutr Biochem 22: 293-299.

37. MacKenzie TN, Mujumdar N, Banerjee S, Sangwan V, Sarver A, et al. (2013) Triptolide induces the expression of miR-142-3p: A negative regulator of heat shock protein 70 and pancreatic cancer cell proliferation. Mol Cancer 12: 1266-1275.

38. Appari M, Babu KR, Kaczorowski A, Gross W, Herr I (2014) Sulforaphane, quercetin and catechins complement each other in elimination of advanced pancreatic cancer by mir-let-7 induction and k-ras inhibition. Int J Oncol 45: 1391-1400.

39. Nwaeburu CC, Abukiwan A, Zhao Z, Herr I (2017) Quercetin-induced miR-200b-3p regulates the mode of self-renewing divisions in pancreatic cancer. Mol Cancer 16: 23.

40. Sonoki H, Sato T, Endo S, Matsunaga T, Yamaguchi M, et al. (2015) Quercetin decreases claudin-2 expression mediated by up-regulation of microrna miR-16 in lung adenocarcinoma a549 cells. Nutrients 7: 4578-4592.

41. Zhang X, Guo Q, Chen J, Chen Z (2015) Quercetin enhances cisplatin sensitivity of human osteosarcoma cells by modulating microrna-217-kras axis. Mol Cells 38: 638642

42. Zhou J, Gong J, Ding C, Chen G (2015) Quercetin induces the apoptosis of human ovarian carcinoma cells by upregulating the expression of microrna-145. Mol Med Rep 12: 3127-3131.

43. Tao SF, He HF, Chen Q (2015) Quercetin inhibits proliferation and invasion acts by up-regulating mir-146a in human breast cancer cells. Mol Cell Biochem 402: 93-100. 
44. Manach C, Williamson G, Morand C, Scalbert A, Rémésy C (2005) Bioavailability and bioefficacy of polyphenols in humans. I. Review of 97 bioavailability studies. $\mathrm{Am}$ J Clin Nutr 81: 230S-242S

45. Arola-Arnal A, Blade C (2011) Proanthocyanidins modulate microRNA expression in human HepG2 cells. PLOS ONE 6: e25982.

46. Arffa ML, Zapf MA, Kothari AN, Chang V, Gupta GN, et al. (2016) Epigallocatechin-3gallate upregulates miR-221 to inhibit osteopontin-dependent hepatic fibrosis. PLoS ONE 11: $\mathrm{e} 0167435$.

47. Shin S, Kim K, Lee MJ, Lee J, Choi S, et al. (2016) Epigallocatechin gallate-mediated alteration of the microrna expression profile in $5 \alpha$-dihydrotestosterone-treated human dermal papilla cells. Ann Dermatol 28: 327-334.

48. Gallelli L, Cione E, Caroleo MC, Carotenuto M, Lagana P, et al. (2017) MicroRNAs to monitor pain-migraine and drug treatment. Microrna 6: 152-156.

49. Yang J, Cao Y, Sun J, Zhang Y (2010) Curcumin reduces the expression of Bcl-2 by upregulating miR-15a and miR-16 in MCF-7 cells. Medical Oncol 27: 1114-1118.

50. Reuter S, Gupta SC, Park B, Goel A, Aggarwal BB (2011) Epigenetic changes induced by curcumin and other natural compounds. Genes Nutr 6: 93-108.

51. Subramaniam D, Ponnurangam S, Ramamoorthy P, Standing D, Battafarano RJ, et al. (2012) Curcumin induces cell death in esophageal cancer cells through modulating Notch signaling. PLoS One 7: e30590.

52. Sun M, Estrov Z, Ji Y, Coombes KR, Harris DH, Kurzrock R (2008) Curcumin (diferuloylmethane) alters the expression profiles of microRNAs in human pancreatic cancer cells. Mol Cancer Therapeutics 7: 464-473.

53. Kronski E, Fiori ME, Barbieri O, Astigiano S, Mirisola V, et al. (2014) miR-181b is induced by the chemopreventive polyphenol curcumin and inhibits breast cancer metastasis via down-regulation of the inflammatory cytokines CXCL1 and -2. Mol Oncol 8: 581-595.

54. Tian L, Song Z, Shao W, Du WW, Zhao LR, et al. (2017) Curcumin represses mouse 3T3-L1 cell adipogenic differentiation via inhibiting miR-17-5p and stimulating the Wnt signalling pathway effector Tcf712. Cell Death Dis 8: e2559.

55. Mirzaei H, Masoudifar A, Sahebkar A, Zare N, Sadri Nahand J, et al. (2018) Microrna: A novel target of curcumin in cancer therapy. J Cell Physi 233: 3004-3015.

56. Goswami SK, Das DK (2009) Resveratrol and chemoprevention. Cancer Lett 284: 1-6.

57. Tili E, Michaille JJ, Alder H, Volinia S, Delmas D, et al. (2010) Resveratrol modulates the levels of microRNAs targeting genes encoding tumor-suppressors and effectors of TGF $\beta$ signaling pathway in SW480 cells. Biochem Pharmacol 80: 2057-2065.

58. Kumazaki M, Noguchi S, Yasui Y, Iwasaki J, Shinohara H, et al. (2013) Anti-cancer effects of naturally occurring compounds through modulation of signal transduction and miRNA expression in human colon cancer cells. J Nutr Biochem 24: 1849-1858.

59. Tili E, Michaille JJ (2011) Resveratrol, microRNAs, inflammation, and cancer. $J$ Nucleic Acids 102431: 1-9.

60. Kumar A, Rimando AM, Levenson AS (2017) Resveratrol and pterostilbene as a microRNA-mediated chemo-preventive and therapeutic strategy in prostate cancer. Ann New York Acad Sci 1403: 15-26.

61. Wu F, Cui L (2017) Resveratrol suppresses melanoma by inhibiting nf- $\mathrm{kB} / \mathrm{miR}-221$ and inducing tfg expression. Arch Dermatol Res 309: 823-831.

62. Bai T, Dong DS, Pei L (2014) Synergistic antitumor activity of resveratrol and miR-200c in human lung cancer. Oncol Rep 31: 2293-2297.

63. Venkatadri R, Muni T, Iyer AK, Yakisich JS, Azad N (2016) Role of apoptosis-related miRNAs in resveratrol induced breast cancer cell death. Cell Death Dis 7: e2104.

64. Akao Y, Nakagawa Y, Iinuma M, Nozawa Y (2008) Anti-cancer effects of xanthones from pericarps of mangosteen. Int J Mol Sci 9: 355-370.

65. Yang J, Liu RH, Halim L (2009) Antioxidant and antiproliferative activities of common edible nut seeds. LWT Food Sci Technol 42: 1-8.

66. Nakagawa Y, Iinuma M, Naoe T, Nozawa Y, Akao Y (2007) Characterized mechanism of $\alpha$-mangostin-induced cell death: Caspase-independent apoptosis with release of endonuclease- $\mathrm{G}$ from mitochondria and increased miR-143 expression in human colorectal cancer DLD-1 cells. Bioorg Med Chem 15: 5620-5628.

67. Kumazaki M, Shinohara H, Taniguchi K, Ueda H, Nishi M, et al. (2015) Anti-cancer effects of naturally occurring compounds through modulation of signal transduction and miRNA expression in human colon cancer cells. Oncotarget 6: 25828-25842.
68. Sun Y, Zuo L, Xu C, Shen T, Pan H, et al. (2002) Apoptosis and differentiation induced by sodium selenite combined with all-trans retinoic acid (ATRA) in NB4 cells. Zhonghua Xиe Ye Xue Za Zhi 23: 628-630.

69. Alvarez-Díaz S, Valle N, Ferrer-Mayorga G, Lombardía L, Herrera M, et al. (2012) MicroRNA-22 is induced by vitamin D and contributes to its antiproliferative, antimigratory and gene regulatory effects in colon cancer cells. Hum Mol Genet 21: 2157-2165.

70. Garzon R, Pichiorri F, Palumbo T, Visentini M, Aqeilan R, et al. (2007) MicroRNA gene expression during retinoic acid-induced differentiation of human acute promyelocytic leukemia. Oncogene 26: 4148-4157.

71. Rossi A, D'Urso OF, Gatto G, Poltronieri P, Ferracin M, et al. (2010) Noncoding RNAs change their expression profile after retinoid induced differentiation of the promyelocytic cell line NB4. BMC Res Notes 3: 24.

72. Terao M, Fratelli M, Kurosaki M, Zanetti A, Guarnaccia V, et al. (2011) Induction of miR-21 by retinoic acid in estrogen receptor-positive breast carcinoma cells: biological correlates and molecular targets. J Biol Chem 286: 4027-4042.

73. Dambal S, Giangrecom AA, Acosta AM, Fairchild A, Richards Z, et al. (2017) microRNAs and DICER1 are regulated by 1,25 -dihydroxyvitamin D in prostate stroma. J Steroid Biochem Mol Biol 167: 192-202.

74. Fleet JC, Desmet M, Johnson R, Li Y (2012) Vitamin D and cancer: a review of molecular mechanisms. Biochem $J$ 441: 61-76.

75. Garland CF, French CB, Baggerly LL, Heaney RP (2011) Vitamin D supplement doses and serum 25-hydroxyvitamin $\mathrm{D}$ in the range associated with cancer prevention. Anticancer Res 31: 607-611.

76. Wang X, Gocek E, Liu CG, Studzinski GP (2009) MicroRNAs181 regulate the expression of p27Kip1 in human myeloid leukemia cells induced to differentiate by 1 , 25-dihydroxyvitamin D3. Cell Cycle 8: 736-741.

77. Kempinska-Podhorodecka A, Milkiewicz M, Wasik U, Ligocka J, Zawadzki M, et al. (2017) Decreased expression of vitamin D receptor affects an immune response in primary biliary cholangitis via the VDR-miRNA155-SOCS1 pathway. Int $J$ Mol Sci 18: 289.

78. Panizo S, Carrillo Lopez N, Naves Diaz M, Solache Berrocal G, Martinez Arias L, et al. (2017) Regulation of miR-29b and miR-30c by vitamin D receptor activators contributes to attenuate uraemia-induced cardiac fibrosis. Nephrol Dial Transplant 32: 1831-1840.

79. Pogribny IP, Tryndyak VP, Ross SA, Beland FA (2008) Differential expression of microRNAs during hepatocarcinogenesis induced by methyl deficiency in rats. Nutr Rev 66: S33-S35.

80. West NJ, Clark SK, Phillips RKS, Hutchinson JM, Leicester RJ, et al. (2010) Eicosapentaenoic acid reduces rectal polyp number and size in familial adenomatous polyposis. Gut 59: 918-925.

81. Leaver HA, Wharton SB, Bell HS, Leaver Yap IM, Whittle IR (2002) Highly unsaturated fatty acid induced tumour regression in glioma pharmacodynamics and bioavailability of gamma linolenic acid in an implantation glioma model effects on tumour biomass, apoptosis and neuronal tissue histology. Prostaglandins Leukot Essent FattyAcids 67: 283-292.

82. Roush S, Slack FJ (2008) The let-7 family of microRNAs. Trends Cell Biol 18: 505 516.

83. Davidson LA, Wang N, Shah MS, Lupton JR, Ivanov I, et al. (2009) N-3 Polyunsaturated fatty acids modulate carcinogen-directed non-coding microRNA signatures in rat colon. Carcinogenesis 30: 2077-2084.

84. Crim KC, Sanders LM, Hong MY, Taddeo SS, Turner ND, et al. (2008) Upregulation of $\mathrm{p} 21 \mathrm{Waf} 1 / \mathrm{Cip} 1$ expression in vivo by butyrate administration can be chemoprotective or chemopromotive depending on the lipid component of the diet. Carcinogenesis 29: $1415-1420$

85. Shah MS, Schwartz SL, Zhao C, Davidson LA, Zhou B, et al. (2011) Integrated microRNA and mRNA expression profiling in a rat colon carcinogenesis model: Effect of a chemo-protective diet. Physiol Genom 43: 640-654.

86. Vinciguerra M, Sgroi A, Veyrat-Durebex C, Rubbia Brandt L, Buhler LH, et al. (2009) Unsaturated fatty acids inhibit the expression of tumor suppressor phosphatase and tensin homolog (PTEN) via microRNA-21 up-regulation in hepatocytes. Hepatology 49: 1176-1184.

87. Le Leu RK, Brown IL, Hu Y, Esterman A, Young GP (2007) Suppression of azoxymethane-induced colon cancer development in rats by dietary resistant starch. Cancer Biol Ther 6: 1621-1626. 
88. Comalada M, Bailón E, de Haro O, Lara-Villoslada F, Xaus J, et al. (2007) The effects of short-chain fatty acids on colon epithelial proliferation and survival depend on the cellular phenotype. J Cancer Res Clin Oncol 133: 211-211.

89. Humphreys KJ, Cobiac L, Le Leu RK, Van der Hoek MB, Michael MZ (2013) Histone deacetylase inhibition in colorectal cancer cells reveals competing roles for members of the oncogenic miR-17-92 cluster. Mol Carcinog 52: 459-474.

90. Hu S, Dong TS, Dalal SR, Wu F, Bissonnette M, et al. (2011) The microbe-derived short chain fatty acid butyrate targets miRNA-dependent $\mathrm{p} 21$ gene expression in human colon cancer. PLoS One 6: e16221.

91. Flores-Mateo G, Navas-Acien A, Pastor-Barriuso R, Guallar E (2006) Selenium and coronary heart disease: a meta-analysis. Am J Clin Nutr 84: 762-773.

92. Bleys J, Navas-Acien A, Guallar E (2008) Serum selenium levels and all-cause, cancer, and cardiovascular mortality among US adults. Arch Intern Med 68: 404-410.

93. Rayman MP (2000) The importance of selenium to human health. Lancet 356: 233-241.

94. Xing Y, Liu Z, Yang G, Gao D, Niu X (2015) MicroRNA expression profiles in rats with selenium deficiency and the possible role of the $\mathrm{Wnt} / \beta$-catenin signaling pathway in cardiac dysfunction. Int J Mol Med 35: 143-152.

95. Chasapis CT, Loutsidou AC, Spiliopoulou CA, Stefanidou ME (2012) Zinc and human health: an update. Arch Toxicol 86: 521-534.

96. Ryu MS, Langkamp Henken B, Chang SM, Shankar MN, Cousins RJ (2011) Genomic analysis, cytokine expression, and microRNA profiling reveal biomarkers of human dietary zinc depletion and homeostasis. Proc Natl Acad Sci USA 108: 20970-20975.

97. Keshavarzi M, Darijani M, Momeni F, Moradi P, Ebrahimnejad H, et al. (2017) Molecular imaging and oral cancer diagnosis and therapy. J Cell Biochem 8: 30553060 .

98. Rabieian R, Boshtam M, Zareei M, Kouhpayeh S, Masoudifar A, et al. (2017) Plasminogen activator inhibitor type-1 as a regulator of fibrosis. $J$ Cell Biochem 18: 26146.

99. Gholamin S, Mirzaei H, Razavi SM, Hassanian SM, Saadatpour L, et al. (2017) GD2-targeted immunotherapy and potential value of circulating microRNAs in neuroblastoma. J Cell Physiol 1: 25793.

100. Cui J, Zhou B, Ross SA, Zempleni J (2017) Nutrition, microRNAs, and human health. Adv Nutr 8: 105-112.

101. Keshavarzi M, Sorayayi S, Jafar Rezaei M, Mohammadi M, Ghaderi A, et al. (2017) MicroRNAs-based imaging techniques in cancer diagnosis and therapy. $J$ Cell Biochem 29: 26012.

102. Nolte-'t Hoen EN, Van Rooij E, Bushell M, Zhang CY, Dashwood RH, et al. (2015) The role of microRNA in nutritional control. J Intern Med 278: 99-109.

103. Zhu H, Dougherty U, Robinson V, Mustafi R, Pekow J, et al. (2011) EGFR signals downregulate tumor suppressors miR-143 and miR-145 in Western diet-promoted murine colon cancer: role of G1 regulators. Mol Cancer Res 9: 960-975.

104. Marsit CJ, Eddy K, Kelsey KT (2006) MicroRNA responses to cellular stress. Cancer Res 66: 10843-10848.

105. Gaedicke S, Zhang X, Schmelzer C, Lou Y, Doering F, et al. (2008) Vitamin E dependent microRNA regulation in rat liver. FEBS Lett 582: 3542-3546.

106. Chen J, Xu T, Chen C (2015) The critical roles of miR-21 in anti-cancer effects of curcumin. Ann Transl Med 3: 2305-5839.

107. Melnik BC (2015) MiR-21: an environmental driver of malignant melanoma? $J$ Transl Med 13: 015-0570.

108. Roy S, Yu Y, Padhye SB, Sarkar FH, Majumdar AP (2013) Difluorinated-curcumin (CDF) restores PTEN expression in colon cancer cells by down-regulating miR-21. PLoS One 8: e68543

109. Yang CH, Yue J, Sims M, Pfeffer LM (2013) The curcumin analog EF24 targets NF-kappaB and miRNA-21, and has potent anticancer activity in vitro and in vivo. PLoS One 8: e71130.
110. Schulte C, Karakas M, Zeller T (2017) microRNAs in cardiovascular diseaseClinical application. Clin Chem Lab Med 55: 687-704.

111. Wojciechowska A, Braniewska A, Kozar-Kaminska K (2017) MicroRNA in cardiovascular biology and disease. Adv Clin Exp Med 26: 865-874.

112. Ye Y, Perez Polo JR, Qian J, Birnbaum Y (2011) The role of microRNA in modulating myocardial ischemia reperfusion injury. Physiol Genom 43: 534-542.

113. Wang H, Cai J (2017) The role of microRNAs in heart failure. Biochim Biophys Acta Mol Basis Dis 1863: 2019-2030.

114. Zhao Y, Ransom JF, Li A, Vedantham V, von Drehle M, et al. (2007) Dysregulation of cardiogenesis, cardiac conduction, and cell cycle in mice lacking miRNA-1-2. Cell 129: 303-317.

115. Ikeda S, He A, Kong SW, Lu J, Bejar R, et al. (2009) MicroRNA-1 negatively regulates expression of the hypertrophy-associated calmodulin and Mef2a genes. Mol Cell Biol 29: 2193-2204.

116. Thum T, Gross C, Fiedler J, Fischer T, Kissler S, et al. (2008) MicroRNA-21 contributes to myocardial disease by stimulating MAP kinase signalling in fibroblasts. Nature 456: 980-984.

117. Jensen MD, Ryan DH, Apovian CM, Ard JD, Comuzzie AG, et al. (2014) AHA/ACC TOS guideline for the management of overweight and obesity in adults: A report of the American College of cardiology/American Heart Association task force on practice guidelines and the obesity society. Circulation 129: 1-70.

118. Xie H, Sun L, Lodish HF (2009) Targeting microRNAs in obesity. Expert Opin Ther Targets 13: 1227-1238.

119. Y, Yu S, Li H, Xiang H, Peng J, et al. (2014) MicroRNAs: Emerging roles in adipogenesis and obesity. Cell Signal 26: 1888-1896.

120. Gregor MF, Hotamisligil GS (2011) Inflammatory mechanisms in obesity. Annu Rev Immunol 29: 415-445.

121. Iacomino G, Russo P, Stillitano I, Lauria F, Marena P, et al. (2016) Circulating microRNAs are deregulated in overweight/obese children: preliminary results of the I. Family study. Genes Nutr 11: 7. [Crossref]

122. Ortega FJ, Mercader JM, Catalán V, Moreno Navarrete JM, Pueyo N, et al. (2013) Targeting the circulating microRNA signature of obesity. Clin Chem 59: 781-92. [Crossref]

123. Kilic ID, Dodurga Y, Uludag B, Alihanoglu YI, Yildiz BS, et al. (2015) microRNA -143 and -223 in obesity. Gene 560: 140-142. [Crossref]

124. Milagro FI, Miranda J, Portillo MP, Fernandez Quintela A, Campión J, et al. (2013) High-throughput sequencing of microRNAs in peripheral blood mononuclear cells: identification of potential weight loss biomarkers. PLoS One 8: e54319. [Crossref]

125. Kumar S (2013) The role of biopesticides in sustainably feeding the nine billion global populations. J Biofertil Biopestici 4: e114.

126. Kumar S (2013) Biopesticides: a need for food and environmental safety. J Biofertil Biopestic 3: 1-3.

127. Kumar S (2015) Biopesticide: an environment friendly pest management strategy. $J$ Biofertil Biopestic 6: e127.

128. Kumar G, Singh A, Vinutha T, Kumar S, Kumar RR, et al. (2017) Possible role of miRNAs and their targets, in modulating leaf morphology and plant growth during leaf curl virus infection in tomato. Indian J Plant Physiol 22: 608-615.

129. Kumar S (2018) Epigenomics for crop improvement: current status and future perspectives. J Genet Cell Biol 3: 128-134.

130. Kumar S 92019) Genome editing to epigenome editing: towards unravelling the enigmas in developmental biology. Trends Develop Biol 12: 1-8.

131. Kumar S (2012) Biosafety issues in laboratory research. Biosafety 1: 1-2.

132. Kumar S (2014) Biosafety issues of genetically modified organisms. Biosafety 3 : $\mathrm{e} 150$.

Copyright: (C2020 Kaur S. This is an open-access article distributed under the terms of the Creative Commons Attribution License, which permits unrestricted use, distribution, and reproduction in any medium, provided the original author and source are credited. 